\section{NO CEREBRAL WHITE MATTER DAMAGE DUE TO CONS SEPSIS IN PRETERM INFANTS DETERMINED BY APPARANT DIFUSSION COEFFICIENT (ADC) ON MRI}

M. Hemels ${ }^{1}$, J. Nijman ${ }^{1}$, A. Leemans ${ }^{2}$, B. van Kooij ${ }^{1}$, M. Benders ${ }^{1}$, A. van den Hoogen ${ }^{1}$, M. Verboon-Maciolek ${ }^{1}$, L. de Vries ${ }^{1}$, T. Krediet ${ }^{1}$, F. Groenendaal ${ }^{1}$

${ }^{1}$ Neonatology, ${ }^{2}$ Image Sciences Institute, University Medical Center, Utrecht, The Netherlands

Background and aims: Neonatal sepsis may cause cerebral white matter (WM) damage in preterm infants, compromising outcome. Coagulase-negative staphylococcal (CONS) sepsis is a frequent cause of morbidity in preterm infants, however generally not developing into a fulminant disease. To determine the impact of CONS sepsis on cerebral WM, the ADC of $3 \mathrm{WM}$ regions was measured using diffusion-weighted MRI (DW-MRI) performed at term-equivalent age.

Methods: Cerebral DW-MRI was performed routinely in 81 preterm infants (GA<31 weeks). Four infants with cerebral white matter damage due to venous infarction or hydrocephalus, before CONS sepsis occurred in 1, were excluded. The ADC of frontal, parietal and occipital WM was calculated in 31 infants with CONS sepsis and 50 infants without sepsis.

Results: $A D C$ values in parietal WM were significantly lower as compared to frontal or occipital WM in both groups $(p<0.001)$, indicating developmental differences (table 1). No differences were found in ADC values of infants with or without CONS sepsis in all 3 regions of cerebral WM.

\begin{tabular}{|c|c|c|c|}
\hline $\begin{array}{c}\text { ADC } \times 10- \\
\text { 3mm2/s } \\
(\mathrm{mean} \pm \\
\mathrm{SD})\end{array}$ & $\begin{array}{c}\text { CONS } \\
(\mathrm{N}=37)\end{array}$ & $\begin{array}{c}\text { No CONS } \\
(\mathrm{N}=50)\end{array}$ & P-value \\
\hline Total & $\begin{array}{c}1.587 \pm \\
0.088\end{array}$ & $\begin{array}{c}1.581 \pm \\
0.121\end{array}$ & 0.805 \\
\hline Frontal & $\begin{array}{c}1.636 \pm \\
0.122\end{array}$ & $\begin{array}{c}1.663 \pm \\
0.148\end{array}$ & 0.394 \\
\hline Parietal & $\begin{array}{c}1.494^{*} \pm \\
0.136\end{array}$ & $\begin{array}{c}1.470^{*} \pm \\
0.147\end{array}$ & 0.456 \\
\hline Occipital & $\begin{array}{c}1.632 \pm \\
0.126\end{array}$ & $\begin{array}{c}1.611 \pm \\
0.157\end{array}$ & 0.526 \\
\hline
\end{tabular}

[Table 1] $\mathrm{p}<0.001$ parietal vs. frontal and occipital
Conclusions: CONS sepsis in preterm infants is not associated with cerebral white matter damage as determined by ADCs in cerebral MRI at termequivalent age.

600

\section{PERIVENTRICULAR LEUCOMALATY IN PRETERM BABIES}

N. Zeka, R. Bejiqi, R. Retkoceri, B. Syla, M. Shala, M. Azemi, A. Gerguri, A. Maloku-Ceku, M. Berisha

\section{Children's Clinic, Pristina, Albania}

Introduction: Periventricular leucomalatio (PVL) is a serious damage of brain that occurs during antenatal, perinatal and postnatal period. In preterm babies under 32 gestational weeks, we have $4-9 \%$ of PVL.

In term babies, this kind of damage is very rare 0.9 $2 \%$. In $35-90 \%$ of cases, damage can cause severe changes, which clinically are express as spastic diplegy and cerebral palsy.

Aims: To look PVL incidence in preterm babies and relation between results of hemoculture and type of PVL.

Material and Methods: in our annual study (January 2008-january 2009) we examined 200 preterm babies hospitalised in our Clinic. Babies were 2835 gestational weeks (mean 31 weeks) weight 900 2500 gr. (mean 1600 gr.), at all preterm babies we made brain ultrasound with probe frequency 5.5$7.5 \mathrm{MHz}$.

Results: PVL is developing at 22 cases $(11 \%)$ and according to sex: 12 males and 10 females. From them 14 were PVL of I-st and II-nd type and eight cases with III-rd type. From this number 17 or $75 \%$ had positive hemoculture. We had a significant relation between positive hemoculture and third type of PVL, which results with 7 cases or $88 \%$. In addition, the size of cyst play important role in prognosis, were cysts larger than $1 \mathrm{~cm}$ give permanent changes also depend on localisation.

Conclusion: PVL is very often at preterm babies and our results show relation between results of hemoculture and type of PVL.

Key words: periventricular leucomalatio, preterm, hemoculture. 